\title{
Lifelong Non-Drinker
}

National Cancer Institute

\section{Source}

National Cancer Institute. Lifelong Non-Drinker. NCI Thesaurus. Code C126380.

An individual who does not drink at the present time and who claims that they have never been a drinker. 